\title{
Electronic cigarettes
}

\author{
Jennifer L. Reed PhD, Alan A. Gervais BSP, Robert D. Reid PhD MBA
}

See also the editorial by Stanbrook on page 1379 and at www.cmaj.ca/lookup/doi/10.1503/cmaj.131469

\section{Electronic (e-) cigarettes are cigarette-shaped canisters used to simulate the action of ciga- rette smoking}

Batteries within the canisters heat up fluid-filled cartridges that contain varying concentrations of flavouring agents, propylene glycol, glycerine, water and other chemicals. ${ }^{1,2}$ Not all e-cigarettes contain nicotine. The cartridge content varies widely according to the manufacturer and distributor. The act of smoking an e-cigarette is called "vaping," because the user inhales vapour, not smoke.

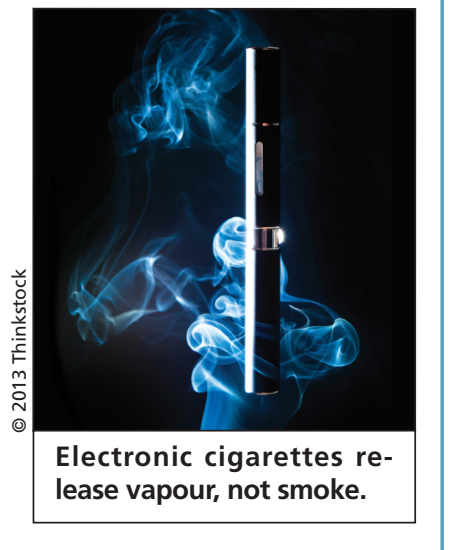

\section{Although perceived by cigarette smokers as a safer alternative to tobacco smoking, e-cigarettes have not been evaluated for their safety}

It is unknown whether inhalation of the mixture of chemicals found in the vapour of e-cigarettes is safe..$^{5}$ Available literature suggests that e-cigarettes contain trace amounts of impurities and carcinogenic tobacco-specific nitrosamines. ${ }^{6}$ Concerns exist regarding the potential to maintain nicotine dependency in current smokers or induce addiction in nonsmokers. ${ }^{3}$

\section{References}

1. Cahn Z, Siegel M. Electronic cigarettes as a harm reduction strategy for tobacco control: A step forward or a repeat of past mistakes? J Public Health Policy 2011;32:16-31.

2. Trehy M, Ye M, Hadwiger M, et al. Analysis of electronic cigarette cartridges, refill solutions, and smoke for nicotine and nicotine related impurities. J Liquid Chromatogr Relat Technol 2011;34:1442-58.

3. Adkison SE, O'Connor RJ, Bansal-Travers M, et al. Electronic nicotine delivery systems: international tobacco control four-country survey. Am J Prev Med 2013;44:207-15.

4. Reid JL, Hammond D, Burkhalter R, et al. Tobacco use in Canada: patterns and trends. Waterloo
E-cigarettes have not been fully evaluated for their efficacy as smoking cessation aids

To date, one 6-month randomized controlled trial has investigated the efficacy of nicotine-containing ecigarettes as a smoking cessation aid; statistical power was insufficient to conclude that e-cigarettes were superior to nicotine patches.?

(ON): Propel Centre for Population Health Impact, University of Waterloo, 2012.

5. Kuschner WG, Reddy S, Mehrotra N, et al. Electronic cigarettes and thirdhand tobacco smoke: two emerging health care challenges for the primary care provider. Int J Gen Med 2011;4:115-20.

6. Vansickel AR, Cobb CO, Weaver MF, et al. A clinical laboratory model for evaluating the acute effects of electronic "cigarettes": nicotine delivery profile and cardiovascular and subjective effects. Cancer Epidemiol Biomarkers Prev 2010;19:1945-53. cigarettes for smoking cessation: a randomized controlled trial. Lancet [Epub ahead of print 2013 Sept. 9].
7. Bullen C, Howe C, Laugesen M, et al. Electronic

\section{E-cigarettes are not regulated or} approved for sale in Canada

Although not approved for sale in Canada, e-cigarettes are readily available online and through retail outlets. A recent 4-country survey of current and former smokers showed that $40 \%$ of the 1581 Canadians surveyed were aware of e-cigarettes and $10 \%$ had tried them. ${ }^{3}$ Although the prevalence of cigarette smoking has decreased over the past few decades, ${ }^{4}$ consumer interest in e-cigarettes is rising. ${ }^{5}$

\section{Effective smoking cessation inter- ventions are available for smo- kers wishing to quit \\ Several pharmacologic and behav- ioural interventions have been found to improve smoking cessation rates (see Appendix 1, available at www.cmaj.ca/lookup/suppl/doi:10 $.1503 / \mathrm{cmaj} .130806 /-/ \mathrm{DC} 1)$. These strategies help patients manage nicotine withdrawal symptoms, learn behavioural self-regulation skills and provide instrumental social support.}

\section{Competing interests: None declared.}

This article has been peer reviewed.

Affiliation: Minto Prevention and Rehabilitation Centre, University of Ottawa Heart Institute, Ottawa, Ont.

Correspondence to: Jennifer L. Reed, jreed@ottawaheart.ca

CMAJ 2013. DOI:10.1503/cmaj.130806 